\title{
Article
}

\section{1,8-Substituted anthraquinones, anthrones and bianthrones as potential non-azole leads against fungal infections}

Jalab, Murhaf, Critchley, Megan, Taylor, Charlotte May, Lawrence, Clare Louise and Smith, Robert B

Available at http://clok.uclan.ac.uk/29449/

Jalab, Murhaf, Critchley, Megan, Taylor, Charlotte May, Lawrence, Clare Louise ORCID: 0000-0003-0170-0079 and Smith, Robert B ORCID: 0000-0002-28295360 (2019) 1,8-Substituted anthraquinones, anthrones and bianthrones as potential non-azole leads against fungal infections. Bioorganic chemistry, 91 . p. 103151. ISSN 0045-2068

It is advisable to refer to the publisher's version if you intend to cite from the work. http://dx.doi.org/10.1016/j.bioorg.2019.103151

For more information about UCLan's research in this area go to

http://www.uclan.ac.uk/researchgroups/ and search for <name of research Group>.

For information about Research generally at UCLan please go to http://www.uclan.ac.uk/research/

All outputs in CLoK are protected by Intellectual Property Rights law, including Copyright law. Copyright, IPR and Moral Rights for the works on this site are retained by the individual authors and/or other copyright owners. Terms and conditions for use of this material are defined in the policies page. 


\title{
1,8-Substituted Anthraquinones, Anthrones and Bianthrones as Potential Non-Azole Leads against Fungal Infections
}

\author{
Murhaf Jalab, ${ }^{a}$ Megan E. Critchley, ${ }^{b}$ Charlotte M. Taylor, ${ }^{b}$ Clare L. Lawrence, ${ }^{a}$ \\ and Robert B. Smith ${ }^{\mathrm{b}^{*}}$
}

aSchool of Pharmacy and Biomedical Sciences, University of Central Lancashire, Preston, PR1 2HE, UK

${ }^{b}$ Chemistry, School of Physical Sciences and Computing, University of Central Lancashire, Preston, PR1 2HE, UK

Corresponding Author: rbsmith@uclan.ac.uk

Tel: +44 (0)1772-894384

\begin{abstract}
The synthesis of a variety of 1,8-substituted anthraquinones, anthrones and bianthrones and their potential as antifungal agents is evaluated. Preliminary screening against Schizosaccharomyces pombe (S. pombe), a fission yeast, and Saccharomyces cerevisiae (S. cerevisiae), a budding yeast, is reported. Both these yeast species demonstrate close homologue to a number of pathogenic fungi.
\end{abstract}

\section{Keywords}

Antifungal; Anthraquinones; Anthrones; Bianthrones; Non-Azole; Yeasts

\section{Submitted to}

Bioorganic Chemistry

- Short Communication - 
Fungal infections continue to be a serious problem for modern-day healthcare with incidences rising notably over the last decade, as resistance to classical antifungals has become more apparent. ${ }^{[1-3]}$ This is combined with the increased susceptibility of immunocompromised patients to infection from emerging opportunistic fungal strains ${ }^{[4-7]}$ To counteract this, healthcare professionals and drug companies seek more aggressive forms of chemotherapeutic treatments with the azoles shown to be good candidates. There is no doubt that the azoles drugs have revolutionised clinical mycology, by targeting the biosynthesis of ergosterol. However, these drugs are not without problems including:

1. Toxicity - Although the azoles are competitive inhibitors for fungal CYP51, these drugs also affect mammalian xenobiotic-metabolising CYP enzymes, ${ }^{[8]}$

2. Resistance - The prolonged and overuse of the azoles has led to the emergence of resistant yeast strains. ${ }^{[9,10]}$

With the increase in microbial resistance, there is now a clear and direct need for novel drug candidates to combat this worrying situation with medicinal chemists now focusing their attention towards the areas of semi-synthetic and natural product chemistry.

The quinones, in particular the anthraquinones as shown in Figure 1, are one type of natural product which is well documented for having wide ranging biological properties, these include anti-bacterial, ${ }^{[11]}$ anti-ulcer, ${ }^{[12]}$ anti-cancer, ${ }^{[13]}$ anti-inflammatory ${ }^{[14]}$ and anti-viral[15] activity. Indeed, various natural and synthetic substituted anthraquinones and their phenanthroperylene cousin, hypericin, have also been recorded to have significant antifungal activity. ${ }^{[16-20]}$<smiles>[R]c1cc(O)c2c(c1)C(=O)c1cc([R])cc(O)c1C2=O</smiles>

$\begin{array}{lll}\mathrm{R}_{1} & \mathrm{R}_{2} & \text { Name } \\ \mathrm{COOH} & \mathrm{H} & \text { Rhein } \\ \mathrm{OCH}_{3} & \mathrm{CH}_{3} & \text { Physcion } \\ \mathrm{CH}_{2} \mathrm{OH} & \mathrm{H} & \text { Aloe-emodin } \\ \mathrm{CH}_{3} & \mathrm{H} & \text { Chrysophanol }\end{array}$

Figure 1. Anthraquinones from Rheum emodi (Polygonaceae).

Surprisingly, there is a lack of data on the antifungal activity for the hypericin type intermediates, the anthones and bianthrones. Inspired by this, we have set out to create a small library of structurally similar anthraquinones, anthrones and bianthrones and study their antifungal activity in two different yeast species; Schizosaccharomyces pombe (S. pombe), a fission yeast; Saccharomyces cerevisiae (S. cerevisiae), a budding yeast, both used extensively in eukaryotic microbiological research. These yeast species demonstrate close homologue to a number of pathogenic fungi. For example, S. cerevisiae is a yeast closely related to Candida albicans, a widespread commensal and important pathogen of humans, and S.pombe is closely related to Pneumocystis jiroveci which is a fungal infection of the lungs. ${ }^{[21]} S$. cerevisiae itself is also emerging as an opportunistic pathogen, especially in immunosuppressed and immunocompromised patients and has been associated with fungemia, endocarditis, 
peritonitis, meningitis, ventriculitis, and with polymicrobial fatal pneumonia in AIDS patients. ${ }^{[22,23]}$ These yeast can serve as models to learn more about pathogenic fungi, in particular with regard to regulatory features and drug therapy, because yeast as a fungal species shares many characteristics with its pathogenic relatives. ${ }^{[24]}$ Therefore, the aforementioned yeast can be used as representative species for screening of chemical libraries for fungicidal activity, without exposure to fungi that are harmful to human health. ${ }^{25]}$

Detailed synthetic pathways to target the anthraquinones, anthrones and bianthrones are shown below in Schemes 1.<smiles>Cc1ccc(S(=O)(=O)Oc2cccc3c2C(=O)c2c(O)cccc2C3=O)cc1</smiles>

$5 a$

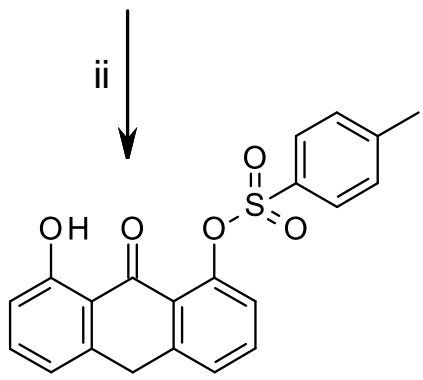

$5 b$

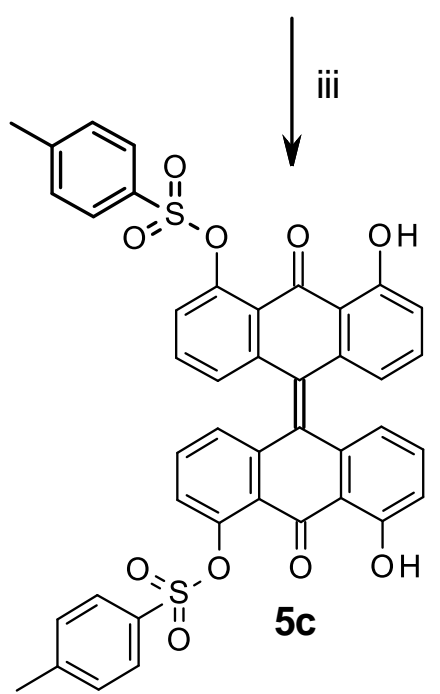<smiles>O=C1c2cccc(O)c2C(=O)c2c(O)cccc21</smiles>

$4 a$<smiles>O=C1c2c(O)cccc2Cc2cccc(O)c21</smiles>

$4 b$<smiles>CC(C)C#N</smiles><smiles>Cc1ccc(S(=O)(=O)Oc2cccc3c2C(=O)c2c(OS(=O)(=O)c4ccc(C)cc4)cccc2C3=O)cc1</smiles>

$6 a$

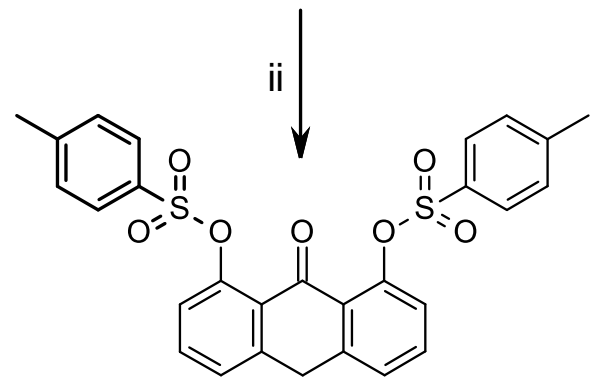

6b<smiles>Cc1ccc(S(=O)(=O)Oc2cccc3c2C(=O)c2c(OS(=O)(=O)c4ccc(C)cc4)cccc2C3=C2c3cccc(OS(=O)(=O)c4ccc(C)cc4)c3C(=O)c3c(OS(=O)(=O)c4ccc(C)cc4)cccc32)cc1</smiles>

i. p-TsCl, $\mathrm{Et}_{3} \mathrm{~N}, \mathrm{MeCN}$; ii. $\mathrm{SnCl}_{2}, \mathrm{HCl}, \mathrm{AcOH}$; iii. $\mathrm{KtOBu}, \mathrm{DMF}, \mathrm{MW}-130^{\circ} \mathrm{C}$; iv. $\mathrm{KtOBu}, \mathrm{DMF}, \mathrm{Reflux}$.

Scheme 1. Synthetic route to the anthroquinones (5a-6a), anthrones (4b-6b) and bianthrones (4c-6c). 
All compounds made within this study followed standard published methodology. The mono and tosylation of 1,8-hydroxyanthroquinone 5a and $6 \mathbf{a}$ was accomplished using reported methods ${ }^{[30,31]}$ with minor modifications from 1,8-dihydroxyanthroquinone (4a). The anthrones (4b-6b and $\mathbf{8 b}$ ) were prepared by chemoselective reduction of the carbonyl group in the $10^{\text {th }}$ position of the 1,8-substituted anthraquinones. This method of chemoselective reduction has been previously demonstrated by the NOE interaction of the newly introduced protons at the $10^{\text {th }}$ position, with the protons in positions 4 and 5. ${ }^{[32]}$ Finally, the bianthrones (4c-6c and $8 \mathbf{c}$ ) was formed either under under wet or microwave conditions using the newly reduced anthrone. ${ }^{[33]}$ Scheme 2 shows the synthesis of emodin bianthrone (8c) from the starting emodin (8a) using the same method as above.

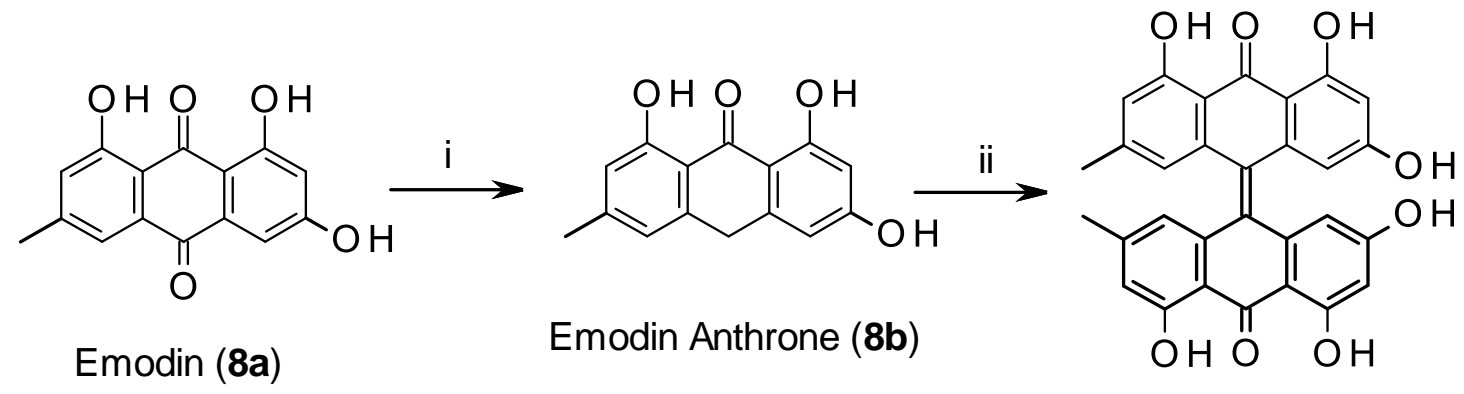

Emodin Bianthrone (8c)

i. $\mathrm{SnCl}_{2}, \mathrm{HCl}, \mathrm{AcOH}$; ii. $\mathrm{KtOBu}, \mathrm{DMF}, \mathrm{MW}-130^{\circ} \mathrm{C}$.

Scheme 2. Synthesis of the emodin anthrone and emodin bianthrone.

One of the main driving factors for the introduction of the tosyloxy functionality was to determine if amino substituents could be added with relative ease. This was studied using the mono-protected $\mathbf{5 a}$, which was independently reacted with three $1^{\circ}$ diamines (ethylenediamine, trimethylenediamine or putrescine) to yield monosubstituted compounds 7a-c as shown in Scheme 3.<smiles>Cc1ccc(S(=O)(=O)Oc2cccc3c2C(=O)c2c(O)cccc2C3=O)cc1</smiles>

5<smiles>[R]Nc1cccc2c1C(=O)c1c(O)cccc1C2=O</smiles>

7
$7 \mathrm{a} \mathrm{R}=\left(\mathrm{CH}_{2}\right)_{2} \mathrm{NH}_{2}$

$7 \mathrm{~b} R=\left(\mathrm{CH}_{2}\right)_{3} \mathrm{NH}_{2}$

$7 \mathrm{c} \mathrm{R}=\left(\mathrm{CH}_{2}\right)_{4} \mathrm{NH}_{2}$

i. $\mathrm{R}-\mathrm{NH}_{2}, \mathrm{DCM}$, Reflux, $2 \mathrm{~h}$

Scheme 3. The synthetic route to the mono substituted aminoanthroquinones (7a-c).

The diamines were used in a 4 molar excess; the ability to remove the tosylate groups being controlled by the selection of an appropriate solvent, which in this case was dichloromethane under reported conditions. ${ }^{[30]}$ The only variation noted using this procedure being the 4 molar excess of the $1^{\circ}$ diamine in comparison to a 250 molar excess of the amine which had been reported. The amine functionalities were not added to the anthrones $(\mathbf{4 b - 6 b})$ or bianthones $(5 \mathbf{c}-\mathbf{6 c})$ due to large scale reactivity and purification issues encountered.

The synthesised compounds were tested in vitro to determine growth inhibitory activity using a standard method. ${ }^{[4,36]}$ Minimum inhibitory concentration (MIC) values were 
determined in sets by comparison with the following compounds, which are intermediates towards the natural product hypericin; emodin (8a), emodin anthrone (8b) and emodin bianthrone (8c). Emodin itself is a well-known antifungal and has been used as a positive control for this study. Its mechanism of action is thought to be due to induction of DNA damage. ${ }^{[34]}$

Table 1 shown below gives the full set of antifungal data collected in this study. The substituted anthraquinones, showed varied results between each of the yeast species. In S. pombe, they were consistently inhibitive at concentrations greater than $1000 \mu \mathrm{M}$ $(4 \mathbf{a}, \mathbf{5} \mathbf{a}$ and $\mathbf{6 a})$. In $S$. cerevisiae, the results were varied, with emodin (8a) and compounds $5 \mathbf{a}$ and $\mathbf{6 a}$ having similar results to that of the $S$. pombe. However, the MIC for $4 a$ in S. cerevisiae was twice that for S.pombe, $2910 \mu \mathrm{M}$ compared to $1460 \mu \mathrm{M}$, with the unsubstituted 9,10-anthroquinone also showing similar results to $\mathbf{4 a}$.

The amine substituted anthraquinones 7 a-c showed a range of activities against both yeast strains tested, but all MICs were lower than $900 \mu \mathrm{M}$. When compared against the control emodin (8a), 7a-c showed lower MICs, with both 7a and 7b being approx. 3.5 times more active against the $S$. pombe $(440 \mu \mathrm{M}$ and $420 \mu \mathrm{M})$ and approx. 1.5 times more active against the $S$. cerevisiae $(886 \mu \mathrm{M}$ and $844 \mu \mathrm{M})$. It's interesting to note 7c showed the greatest activity of the three with the MIC being approx. 6.5 times higher against both yeast species $(200 \mu \mathrm{M})$, when compared to emodin (8a). It is postulated that this is due to increasing the length of amine chain, which will increase the lipophilicity of the molecule, allowing for better membrane penetration. ${ }^{35]}$ Finally, all compounds within this family were fungastatic apart from $\mathbf{7 b}$ and $\mathbf{7 c}$ which were shown to be fungicidal against $S$. pombe alone.

The growth inhibition concentrations for the anthrones are shown alongside $\mathbf{8 b}$. It is interesting to note that $\mathbf{8 b}$ is 13 times more active against $S$. pombe in comparison to the control $\mathbf{8 a}(97.6 \mu \mathrm{M}$ versus $1300 \mu \mathrm{M})$. The anthones $\mathbf{4 b}, \mathbf{5 b}$ and $\mathbf{6 b}(55.3 \mu \mathrm{M}$, $65.7 \mu \mathrm{M}$ and $46.8 \mu \mathrm{M})$ are approx. 1.5 times more active against $S$. pombe when compared to the $\mathbf{8 b}(97.6 \mu \mathrm{M})$ and approx. 20 times more active when compared to $8 \mathbf{a}(1300 \mu \mathrm{M})$. It is also noteworthy that $\mathbf{8 b}(1950 \mu \mathrm{M})$ is less active against $S$. cerevisiae by a factor of 1.5 when compared against $8 \mathbf{a}(1300 \mu \mathrm{M})$, however, $\mathbf{4 b}$ $(553 \mu \mathrm{M}), \mathbf{5 b}(329 \mu \mathrm{M})$ and $\mathbf{6 b}(234 \mu \mathrm{M})$ again show superior activity when compared to both $\mathbf{8 a}$ and $\mathbf{8 b}$ respectively. However, the MICs are still significantly higher than that seen in $S$. pombe. The unsubstituted anthrone followed the same trend as the other compounds but were less active against $S$. pombe in comparison to the other anthrones, whilst showing the same type of activity against $S$. cerevisiae as $\mathbf{4 b}$. All compounds within this family were shown to be fungistatic, apart from $\mathbf{8 b}$ that was fungicidal, against $S$. cerevisiae.

Finally, the antifungal activity of the bianthrones show a variation in results. $8 \mathrm{c}$, the bianthrone substited emodin, was showed to be slightly more active than $\mathbf{8 a}$, the emodin anthraquinone, when compared against both yeast species, $980 \mu \mathrm{M}$ and 1300 $\mu \mathrm{M}$ respectively. Compound $\mathbf{4 c}$ showed to be 13 times more active against $S$. pombe $(140 \mu \mathrm{M})$ and 2 times more active against $S$. cerevisiae $(555 \mu \mathrm{M})$ when compared to the control emodin (8a) and emodin bianthrone (8c). Compound $\mathbf{5 c}$ again showed almost identical activity against both $S$. pombe and $S$. cerevisiae, $460 \mu \mathrm{M}$ and $461 \mu \mathrm{M}$ respectively. The unsubstituted bianthrone gave the lowest activity against both activity $S$. pombe and S. cerevisiae, $1355 \mu \mathrm{M}$ and $2168 \mu \mathrm{M}$ respectively. Finally $6 \mathrm{c}$, showed no growth inhibition at the concentrations tested. All compounds tested within this study, except 6c, were found to be fungistatic in both yeast species. It should be noted that the $c \log P$ data given in Table 1 shows no correlation to the activity. 


\begin{tabular}{|c|c|c|c|c|c|c|c|c|c|}
\hline \multicolumn{10}{|c|}{ Anthraquinones } \\
\hline \multirow[t]{2}{*}{ Compound } & \multirow[t]{2}{*}{$\mathrm{R}^{1}$} & \multirow[t]{2}{*}{$\mathrm{R}^{3}$} & \multirow[t]{2}{*}{$\mathrm{R}^{6}$} & \multirow[t]{2}{*}{$\mathrm{R}^{8}$} & \multirow[t]{2}{*}{ cLogP } & \multicolumn{4}{|c|}{$\mathrm{MIC}(\mu \mathrm{M})$} \\
\hline & & & & & & S. pombe & $S / C$ & S. cerevisiae & $S / C$ \\
\hline 9,10-Anthraquinone & $\mathrm{H}$ & $\mathrm{H}$ & $\mathrm{H}$ & $\mathrm{H}$ & 3.67 & 1250 & $\mathrm{~S}$ & 2001 & $S$ \\
\hline Emodin (8a) & $\mathrm{OH}$ & $\mathrm{OH}$ & $\mathrm{CH}_{3}$ & $\mathrm{OH}$ & 3.01 & 1300 & $S$ & 1300 & $\mathrm{~S}$ \\
\hline $4 a$ & $\mathrm{OH}$ & $\mathrm{H}$ & $\mathrm{H}$ & $\mathrm{OH}$ & 3.13 & 1460 & $S$ & 2910 & $S$ \\
\hline $5 a$ & $\mathrm{OH}$ & $\mathrm{H}$ & $\mathrm{H}$ & OTs & 4.77 & 1770 & $S$ & 1770 & $S$ \\
\hline $6 a$ & OTs & $\mathrm{H}$ & $\mathrm{H}$ & OTs & 6.40 & 1280 & $\mathrm{~S}$ & 1280 & $\mathrm{~S}$ \\
\hline $7 a$ & $\mathrm{OH}$ & $\mathrm{H}$ & $\mathrm{H}$ & $\mathrm{NH}\left(\mathrm{CH}_{2}\right)_{2} \mathrm{NH}_{2}$ & 0.9 & 440 & $S$ & 886 & $S$ \\
\hline $7 \mathrm{~b}$ & $\mathrm{OH}$ & $\mathrm{H}$ & $\mathrm{H}$ & $\mathrm{NH}\left(\mathrm{CH}_{2}\right)_{3} \mathrm{NH}_{2}$ & 1.44 & 420 & C & 844 & $\mathrm{~S}$ \\
\hline $7 \mathrm{c}$ & $\mathrm{OH}$ & $\mathrm{H}$ & $\mathrm{H}$ & $\mathrm{NH}\left(\mathrm{CH}_{2}\right)_{4} \mathrm{NH}_{2}$ & 1.98 & 200 & $\mathrm{C}$ & 201 & $\mathrm{~S}$ \\
\hline \multicolumn{10}{|c|}{ Anthrones } \\
\hline \multirow[t]{2}{*}{ Compound } & \multirow[t]{2}{*}{$\mathrm{R}^{1}$} & \multirow[t]{2}{*}{$\mathrm{R}^{3}$} & \multirow[t]{2}{*}{$\mathrm{R}^{6}$} & \multirow[t]{2}{*}{$\mathrm{R}^{8}$} & \multirow[t]{2}{*}{ cLogP } & \multicolumn{4}{|c|}{$\mathrm{MIC}(\mu \mathrm{M})$} \\
\hline & & & & & & S. pombe & $S / C$ & S. cerevisiae & $S / C$ \\
\hline Anthrone & $\mathrm{H}$ & $\mathrm{H}$ & $\mathrm{H}$ & $\mathrm{H}$ & 3.49 & 267 & $S$ & 534 & $\mathrm{~S}$ \\
\hline Emodin Anthrone (8b) & $\mathrm{OH}$ & $\mathrm{OH}$ & $\mathrm{Me}$ & $\mathrm{OH}$ & 3.25 & 97.6 & $S$ & 1950 & $\mathrm{C}$ \\
\hline $4 \mathrm{~b}$ & $\mathrm{OH}$ & $\mathrm{H}$ & $\mathrm{H}$ & $\mathrm{OH}$ & 3.38 & 55.3 & $S$ & 553 & $S$ \\
\hline $5 b$ & $\mathrm{OH}$ & $\mathrm{H}$ & $\mathrm{H}$ & OTs & 4.80 & 65.7 & $\mathrm{~S}$ & 329 & $\mathrm{~S}$ \\
\hline $6 b$ & OTs & $\mathrm{H}$ & $\mathrm{H}$ & OTs & 6.22 & 46.8 & $S$ & 234 & $S$ \\
\hline \multicolumn{10}{|c|}{ Bianthrones } \\
\hline \multirow[t]{2}{*}{ Compound } & $\mathrm{R}^{1} \& \mathrm{R}^{1}$ & $\mathrm{R}^{3} \& \mathrm{R}^{3}$ & $R^{6} \& R^{6} a$ & $R^{8} \& R^{8} a$ & cLogP & \multicolumn{4}{|c|}{$\mathrm{MIC}(\mu \mathrm{M})$} \\
\hline & a & a & & & & S. pombe & $S / C$ & S. cerevisiae & $S / C$ \\
\hline Bianthrone & $\mathrm{H}$ & $\mathrm{H}$ & $\mathrm{H}$ & $\mathrm{H}$ & 7.69 & 1355 & $S$ & 2168 & $\mathrm{~S}$ \\
\hline Emodin Bianthrone (8c) & $\mathrm{OH}$ & $\mathrm{OH}$ & $\mathrm{Me}$ & $\mathrm{OH}$ & 6.37 & 980 & S & 980 & $S$ \\
\hline $4 c$ & $\mathrm{OH}$ & $\mathrm{H}$ & $\mathrm{H}$ & $\mathrm{OH}$ & 6.62 & 140 & $S$ & 555 & $\mathrm{~S}$ \\
\hline $5 c$ & $\mathrm{OH}$ & $\mathrm{H}$ & $\mathrm{H}$ & OTs & 9.06 & 460 & S & 461 & $S$ \\
\hline $6 c$ & OTs & $\mathrm{H}$ & $\mathrm{H}$ & OTs & 9.82 & $\alpha$ & - & $\alpha$ & - \\
\hline
\end{tabular}

Minimal Inhibitory Growth Concentration (MIC) of synthesised compounds tested in Schizosaccharomyces pombe (S.pombe), Saccharomyces cerevisiae (S. cerevisiae). Cells were inoculated at a concentration of $3 \times 10^{4} / \mathrm{ml}$. Culture media tested were in yeast extract broth (YE) for S.pombe and complex growth media (YPD) for $S$. cerevisiae. Growth of yeast was determined visually after 24 hours incubation at $30{ }^{\circ} \mathrm{C}$. The MIC of the compounds were determined to be the well before yeast growth was first seen. The experiment was repeated three times to ensure reproducibility of the results. Compounds were determined to be fungicidal (C), if no growth was observed, and fungistatic $(S)$, if normal growth was seen after inoculation into fresh media. . $\alpha$ - Growth seen in all wells up to $600 \mu \mathrm{M}$ concentration.

Table 1. Structures and growth inhibitory data for the 1,8-substituted anthroquinones. 
In conclusion, the anthraquinones (5a and $6 \mathbf{a}$ ), anthrones (4b-6b and $8 \mathbf{b}$ ) and bianthrones (4c-6c and $\mathbf{8 c}$ ) were all prepared using literature methods in varying yields from pre-purchased compounds (4a and $\mathbf{8 a}$ ). The synthesis of the monoamino substituted anthraquinones (7a-c) was also successfully accomplished using literature methods with minor modifications. The target anthraquinones, anthrones and bianthrones are important from a structural viewpoint; the toluenesulphonyl functionality allows easy addition of amino functionalities, this has the advantage of greater intrinsic water solubility and allows for further attachments to take place such as amino acids, mono-clonal antibodies etc. This would be advantageous as it would be a route to specific cell targeting. Preliminary screen of all the compounds in this study showed varying levels of antifungal activity, with the control emodin, often showing poorer activity when compared to the other compounds in this study. As highlighted earlier in this study, the mechanism of action of emodin (8a) is thought to be due to induction of DNA damage. ${ }^{[34]}$ However, the compounds shown in this study are fungistatic, thus suggesting an alternative mode of action is highly plausible

It should also be noted that there is no correlation between cLogP data given in Table 1 and compound activity, which might suggest the growth inhibition is not the result of an intracellular mechanism of action. It is clear from these results that the anthrones $(\mathbf{4 b}-\mathbf{6 b})$, the bianthrones $(\mathbf{4 c - 5 c})$ and the amino substituted anthraquinones (7a-c) show promising antifungal activity and should form the structural basis towards possible new antifungal leads.

\section{Notes}

The authors declare no competing financial interest.

\section{Acknowledgement}

The authors would like to thank the Faculty of Science and Technology at the University of Central Lancashire for financially supporting this study. 


\section{References}

1. Wiederhold, NP. The antifungal arsenal: alternative drugs and future targets, International Journal of Antimicrobial Agents. 2018;51:333-339.

2. Ostrosky-Zeichner L, Casadevall A, Galgiani JN, Odds FC, Rex JH. An insight into the antifungal pipeline: selected new molecules and beyond, Nat. Rev. Drug Discovery. 2010;9:719-727.

3. $\quad$ Campoy S, Adrio JL. Antifungals, Biochemical Pharmacology. 2017; 133:86-96.

4. Tyler AR, Okoh AO, Lawrence CL, Jones VC, Moffatt C, Smith RB. N-Alkylated 2,3,3-trimethylindolenines and 2-methylbenzothiazoles. Potential lead compounds in the fight against Saccharomyces cerevisiae infections, European Journal of Medicinal Chemistry. 2013;64:222-227.

5. Kung HC, Huang PY, Chen WT, Ko BS, Chen YS, Chang SC, Chuang YC, 2016 Guidelines for the use of antifungal agents in patients with invasive fungal diseases in Taiwan, Journal of Microbiology. Immunology and Infection. 2018;51:1-176.

6. Puia-Dumitrescu M, Smith PB, Antifungal Drugs in Newborns and Children, Pediatric Clinics of North America. 2017;64:1389-1402.

7. Ajmal S, Mahmood M, Saleh OA, Larson J, Sohail MR. Invasive fungal infections associated with prior respiratory viral infections in immunocompromised hosts, Infection. 2018;46:555-558.

8. Mortimer CG, Wells G, Crochard JP, Stone EL, Bradshaw TD, Stevens MFG, Westwell AD, Antitumor Benzo thiazoles. 26.1 2-(3,4-Dimethoxyphenyl)-5fluorobenzothiazole (GW 610, NSC 721648), a Simple Fluorinated 2Arylbenzothiazole, Shows Potent and Selective Inhibitory Activity against Lung, Colon, and Breast Cancer Cell Lines, J. Med. Chem. 2006;49:179-185.

9. Berger S, El Chazli Y, Babu A.F, Coste AT, Azole Resistance in Aspergillus fumigatus: A Consequence of Antifungal Use in Agriculture?, Front Microbiol. 2017;8:1024.

10. Revie NM, lyer KR, Robbins N, Cowen LE. Antifungal drug resistance: evolution, mechanisms and impact, Current Opinion in Microbiology. 2018;45:70-76.

11. Zhang J, Redman N, Litke AP, Zeng J, Zhan J, Chan KY, Chang CW. Synthesis and antibacterial activity study of a novel class of cationic anthraquinone analogs, Bioorg Med Chem. 2011;19:498-503.

12. Ayo RG. Phytochemical constituents and bioactivities of the extracts of Cassia nigricans Vahl, Journal of Medicinal Plants Research. 2010;4:1339-1348.

13. Cichewicz $\mathrm{RH}$, Zhang $\mathrm{Y}$, Seeram NP, Nair MG. Inhibition of human tumor cell proliferation by novel anthraquinones from day lilies, Life Sci. 2004;74:17911799.

14. Prati F, Bartolini M, Simoni E, Angela De Simone A, Pinto A, Andrisano V, Bolognesi ML. Quinones bearing non-steroidal anti-inflammatory fragments as multitarget ligands for Alzheimer's disease, Bioorg Med Chem Lett. 2013;23:6254-6258. 
15. Zhou M, Xing HH, Yang Y, Wang YD, Zhou K, Dong W, Li GP, Hu WY, Liu Q, Li XM, Hu QF. Three new anthraquinones from the twigs of Cassia fistula and their bioactivities, Journal of Asian Natural Products Research. 2017;19:10731078.

16. Milošević T, Solujić S, Antimicrobial Activity of the HypercumPerforatum L. Plant, Bulletin of the Chemists and Technologists of Macedonia. 2006;25:127130.

17. Abubakar EMM, Antibacterial activity of crude extracts of Euphorbia hirta against some bacteria associated with enteric infections, Journal of Medicinal Plants Research. 2009;3:498-505.

18. Saddiqe Z, Naeem I, Maimoona A. A review of the antibacterial activity of Hypericum perforatum L, Journal of Ethnopharmacology. 2010;131:511-552.

19. Singh DN, Verma N, Raghuwanshi S, Shuklaband PK, Kulshreshth DK. Antifungal anthraquinones from Saprosma fragrans, Bioorg Med Chem Lett. 2006;16:4512-4514.

20. Arif T, Bhosale JD, Kumar N, Mandal TK, Bendre RS, Lavekar GS. Dabur R. Natural products - antifungal agents derived from plants, Journal of Asian Natural Products Research. 2009;11:621-638

21. Anderson JB, Sirjusingh C, Parsons AB, Boone C, Wickens C, Cowen LE, Kohn LM, Mode of Selection and Experimental Evolution of Antifungal Drug Resistance in Saccharomyces cerevisiae, Genetics. 2003;163:1287-1298.

22. Marcet-Houben M, Gabaldón T. The tree versus the forest: the fungal tree of life and the topological diversity within the yeast phylome, PLoS One. 2009;4 1-8.

23. Skovgaard N. New trends in emerging pathogens, International Journal of Food Microbiology, 2007;120:217-224.

24. Hazen KC. New and emerging yeast pathogens. Clinical Microbiology Reviews. 1995;8:462-478.

25. Goldstein AL, McCusker JH, Development of Saccharomyces cerevisiae as a model pathogen. A system for the genetic identification of gene products required for survival in the mammalian host environment, Genetics. 2001;159: 499-513.

26. Lawrence CL, Maekawa H, Worthington JL, Reiter W, Wilkinson CRM, Jones $\mathrm{N}$, Regulation of Schizosaccharomyces pombe Atf1 protein levels by Sty1mediated phosphorylation and heterodimerization with Pcr1, J Biol Chem. 2007;282:5160-5170.

27. Moreno S, Klar A, Nurse P. Molecular genetic analysis of fission yeast Schizosaccharomyces pombe, Methods Enzymol. 1991;194:795-823.

28. Brachmann CB, Davies A, Cost GJ, Caputo E, Li J, Hieter P, Boeke JD. Designer deletion strains derived from Saccharomyces cerevisiae S288C: a useful set of strains and plasmids for PCR-mediated gene disruption and other applications, Yeast. 1998;14:115-132.

29. Treco DA, Lundblad V, Preparation of Yeast Media, In Current Protocols in Molecular Biology. John Wiley \& Sons, Inc.: 2001. 
30. Zielske AG. (Tosyloxy)anthraquinones. Versatile synthons for the preparation of various aminoanthraquinones, J. Org. Chem. 1987;52,1305-1309.

31. Sangthong $\mathrm{S}, \mathrm{Ha} \mathrm{H}$, Teerawattananon T, Ngamrojanavanich N, Neamati N, Muangsin N. Overcoming doxorubicin-resistance in the NCl/ADR-RES model cancer cell line by novel anthracene-9,10-dione derivatives, Bioorg Med Chem Lett. 2013;23:6156-6160.

32. Motoyoshiya J, Masue $\mathrm{Y}$, Nishii $\mathrm{Y}$, Aoyama $\mathrm{H}$. Synthesis of Hypericin via Emodin Anthrone Derived from a Two-fold Diels-Alder Reaction of 1,4Benzoquinone, Natural Product Communications. 2007;2:67-70.

33. Aigner S, Falk H. A microwave-assisted synthesis of phenanthroperylene quinones as exemplified with hypericin, Monatsh Chem. 2008;139:991-993.

34. Sharma R, Tiku AB, Giri A. Pharmacological Properties of Emodin Anthraquinone Derivatives, Journal of Natural Products and Resources. 2017;3:97-101

35. Haraguchi H, Kataoka S, Okamoto S, Hanafi M, Shibata K. Antimicrobial Triterpenes from llex integra and the mechanism of antifungal action, Phytother. Res.1999;13:151-156.

36. The growth inhibitory activity of the compounds were determined by screening S. pombe and S.cerevisiae using the following method: Yeast species were inoculated into relevant media; S. pombe (NJ2 $h$ ura4-D18 leu1-32 ade6-M210 his7-366) ${ }^{[26]}$ into yeast extract broth (YE), ${ }^{[27]}$ and S.cerevisiae (strain BY4741a, a derivative of S288C, (MATahis3 $\Delta 1$ leu2 $\Delta 0$ met15 $\Delta 0$ ura3 $\Delta 0)^{[28]}$ into complex media (YPD). [29] The culture was then incubated for 12 hours at $30^{\circ} \mathrm{C}$ with shaking at $200 \mathrm{rpm}$. Stock solutions of the compounds were prepared in 20\% $(\mathrm{v} / \mathrm{v})$ DMSO and culture media. DMSO and culture media were used as controls for the experiment. $3 \times 10^{4}$ exponential growing yeast cells were transferred into the wells of a 96-well plate. A 1:2 serial dilution of the compounds was then performed. The wells were inspected visually for growth of yeast after 24 hours of incubation at $30{ }^{\circ} \mathrm{C}$. Growth was indicated by full or partial white appearance of yeast on the bottom of the wells. The MIC values of the compounds were determined to be the well before yeast growth was first seen. The experiment was repeated three times to ensure reproducibility of the results. To determine whether compounds had fungistatic or fungicidal activity, cells were taken from the well on the microtitre plate at the concentration where lack of yeast growth was first observed. These cells were inoculated into fresh culture media, to strongly dilute the presence of the compound, and grown for 24 hours at $30^{\circ} \mathrm{C}$ with shaking at 200rpm. Compounds were determined to be fungicidal, if no growth was observed, and fungistatic, if normal growth was seen. 